\section{Dr. Fitzcharles and Dr. Shir reply}

To the Editor:

We appreciate the comments by Dr. Rothschild ${ }^{1}$ regarding the effect of opioids on adherence to an exercise program in patients with fibromyalgia (FM). Dr. Rothschild has suggested that sleep dysfunction due to opioids may be an important factor to explain poor adherence to exercise recommendations. The argument that opioids could accentuate the sleep disorder in persons with FM is correct. Whether sleep disorder per se, by whatever mechanism, is the unique reason to explain both the findings of the study by Kim and colleagues, as well as much of the symptomatology of FM, remains debatable ${ }^{2}$.

Sleep problem is a recognized core symptom of FM, and may manifest as difficulty falling asleep or staying asleep, frequent awakenings, or feeling unrefreshed after a period of sleep ${ }^{3}$. Poor sleep will contribute to fatigue and affect the ability to engage in a physical activity program. By adding another factor that affects sleep, such as opioid medication, the consequences may be compounded. Opioids are known to affect sleep in a number of ways, including reduction in rapid eye movement and slow wave sleep, as well as development of central sleep apnea ${ }^{4,5}$. We therefore entirely agree that disordered sleep may be an additive factor to poor function in patients with FM. However, other side effects of opioids such as drowsiness, fatigue, and depression must also be taken into account. Although never formally tested as a therapy for FM, with the exception of tramadol, opioids in patients with FM are associated with poorer health and psychosocial status and are not recommended by any current FM guidelines ${ }^{6,7}$. Nevertheless, opioids are currently used by almost a third of patients with FM in North America, and are perceived by patients to be among the most effective medications for treatment of $\mathrm{FM}^{2,8}$.

In view of the complexity of FM, compounded by an array of opioid-related adverse effects, it is too simplistic to invoke opioid-induced sleep disturbance as the principle reason for nonadherence to an exercise program. Regardless of the exact or predominant mechanism involved in nonparticipation, we believe that the message of adverse events related to medication use in patients with FM is loud and clear. The effect of medications on symptoms of FM cannot be overestimated, with the knowledge that opioids in particular may contribute to many symptoms prevalent in patients with FM. Any drug treatment used to manage FM must be regularly evaluated for continued efficacy and side effects, with careful attention to ensure that medication side effects do not outweigh the therapeutic benefit.

MARY-ANN FITZCHARLES, MB, ChB, Montreal General Hospital; YORAM SHIR, MD, McGill University, Division of Rheumatology, Montreal, Quebec, Canada. Address correspondence to M.A. Fitzcharles, Montreal General Hospital, 1650 Cedar Ave., Montreal, Quebec

H3G 1A4, Canada. E-mail: mary-ann.fitzcharles@muhc.mcgill.ca

\section{REFERENCES}

1. Rothschild BM. Impairment of motivational efforts: another complication of opioid compromise of sleep quality? J Rheumatol 2018;45:1070-1.

2. Kim S, Slaven JE, Ang DC. Sustained benefits of exercise-based motivational interviewing, but only among nonusers of opioids in patients with fibromyalgia. J Rheumatol 2017;44:505-11.

3. Clauw DJ. Fibromyalgia: a clinical review. JAMA 2014; 311:1547-55.

4. Dimsdale JE, Norman D, DeJardin D, Wallace MS. The effect of opioids on sleep architecture. J Clin Sleep Med 2007;3:33-6.

5. Teichtahl H, Wang D. Sleep-disordered breathing with chronic opioid use. Expert Opin Drug Saf 2007;6:641-9.

6. Macfarlane GJ, Kronisch C, Dean LE, Atzeni F, Häuser W, Fluß E, et al. EULAR revised recommendations for the management of fibromyalgia. Ann Rheum Dis 2017;76:318-28.

7. Fitzcharles MA, Faregh N, Ste-Marie PA, Shir Y. Opioid use in fibromyalgia is associated with negative health related measures in a prospective cohort study. Pain Res Treat 2013;2013:898493.

8. Bennett RM, Jones J, Turk DC, Russell IJ, Matallana L. An internet survey of 2,596 people with fibromyalgia. BMC Musculoskelet Disord 2007;8:27.

J Rheumatol 2018;45:7; doi:10.3899/jrheum.180043 